\title{
Effects of Steam Injection on the Performance of Natural Gas Combined Cycle Power Genertion System
}

\author{
Nitin Varia \\ Department of Automotive, Mechanical and \\ Manufacturing Engineering \\ University of Ontario Institute of Technology \\ Oshawa, L1H 7 K4, Canada \\ Bale V. Reddy \\ Department of Automotive, Mechanical and \\ Manufacturing Engineering \\ University of Ontario Institute of Technology \\ Oshawa, L1H 7 K4, Canada \\ bale.reddy@uoit.ca
}

\author{
Dipal Patel \\ Department of Automotive, Mechanical and \\ Manufacturing Engineering \\ University of Ontario Institute of Technology \\ Oshawa, L1H 7 K4, Canada \\ dipal.patel@uoit.ca \\ T. Srinivas \\ School of Mechanical Sciences \\ Vellore Institute of Technology \\ Vellore, India \\ lsriivast@vit.ac.in
}

\begin{abstract}
In the present work, combined cycle power generation configuration studies with natural gas as a primary fuel. Steam is injected in main combustion chamber and reheat combustion chamber individually and simultaneously to understand the performance of combined cycle work output and greenhouse gas emissions. The effect of pressure ratio, gas turbine inlet temperature on combined cycle work output, thermal efficiency and exergy efficiency carried out with and without steam injection. It is observed that the steam injection increases gas cycle efficiency and decreases the steam cycle efficiency. Ideal pressure ratio found to be 25 in all different combined cycle power generation system configurations. Maximum $\mathrm{CO}_{2}$ emission reduction (7.2\%) occurs when steam injected in reheater combustion chamber.
\end{abstract}

Keywords - combined cycle; steam; turbines; energy efficiency; exergy efficiency

\section{INTRODUCTION}

This Research investigations are conducted to study the combined cycle power generation systems with various options to increase efficiency and to reduce carbon dioxide emissions. Srinivas et. al. [1] conducted parametric simulation of steam injected gas turbine combined cycle. Waldyr [2] compared the humid air turbine (HAT) cycle with simple gas turbine cycle, steam injected gas turbine and also with the combined cycle. Nishida et. al. [3] investigated the performance characteristics of the regenerative steam injected gas turbine system. Shukla and Singh [4] conducted thermodynamic analysis of steam injected gas turbine cycle power plant with inlet air cooling. Bahrami et. al., [5] conducted performance comparison between steam injected gas turbine and combined cycle during frequency drops. Korakianititis et. al. [6] conducted performance investigations for combine-cogeneration power plants with performance enhancements. In the present work the effect of steam injection in main and reheat gas turbine combustion chambers and the role of operating variables for different natural gas fired combined cycle power generation systems are investigated.

\section{COnfriguration And Methodology}

\section{A. Natural gas combined cycle configuration}

Natural gas fired combined power generation systems are gaining popularity due to their higher combustion efficiency and reduced emission. Different combined cycle power generation configurations are considered in the present work and are listed in Table 1. Fig.ure 1 shows the schematic diagram of these configurations.

The topping cycle consists of air compressor $(C 1)$ followed by an intercooler $(I C)$. Air is further compressed in second air compressor $(C 2)$. Compressed air is burned with methane in combustion chamber (CC1). In case of configuration \#2 and \#3 from Table 1, a fraction of a steam $(\zeta)$ is injected in the first combustion chamber. Products of first combustion chamber enters main gas turbine (GT1) and produced work output. Exhaust gas from main gas turbine further burned with methane in second combustion chamber (CC2). In case of configuration $\# 3$, a fraction of steam $(\omega)$ is injected in reheater combustion chamber. Product of reheater combustion chamber enters the reheater gas turbine (GT2) to produce work output. Exhaust gas from gas turbine enters heat recovery steam generator (HRSG) which produces steam in the bottoming cycle. The Steam then enters the steam turbine $(S T)$ and produces work output. Fraction of steam $(\zeta$ and $\omega)$ is taken out at particular pressure and used in topping cycle for power augmentation. Water vapor from steam turbine is then condensed in condenser and recirculates in the 
bottoming cycle through pump. It is assumed that system is operating at steam state steady flow conditions.

TABLE I. CONFIGURATIONS

\begin{tabular}{|c|l|}
\hline Configuration & \multicolumn{1}{c|}{ Description of Study } \\
\hline 1 & $\begin{array}{l}\text { Combustion of air and methane without stream } \\
\text { injection }\end{array}$ \\
\hline 2 & $\begin{array}{l}\text { Combustion of air and methane with steam } \\
\text { injection in main combustion chamber }\end{array}$ \\
\hline 3 & $\begin{array}{l}\text { Combustion of air and methane with steam } \\
\text { injection in main combustion chamber and reheater } \\
\text { combustion chamber }\end{array}$ \\
\hline
\end{tabular}

Figure 1 shows the generalized schematic diagram for all configuration listed in Table 1. Air is compressed from ambient condition into air compressor $(C 1)$ and $(C 2)$. An intercooler $(I C)$ is used between $C 1$ and $C 2$ to bring the air temperature down and to reduce overall compressor work. Compressed air $\left[\phi \mathrm{O}_{2}+\right.$ $(\theta \times 3.76) N_{2}$ ] enters combustion chamber 1 (CC1) and burned with methane fuel $(\alpha)$ at constant pressure. Combusted gas has high thermal energy and expanded partially into Gas Turbine 1 (GT1) to obtain shaft work $\left(\dot{W}_{G T 1}\right)$. Partially expanded gas enters combustion chamber $2(C C 2)$ and burned with methane fuel $(\beta)$ to elevate the thermal energy of the gas. Gas coming out of $C C 2$ is expanded in Gas Turbine 2 (GT2) to obtain shaft work $\left(\dot{W}_{G T 2}\right)$. Gas coming out of GT2 is passed through Heat Recovery Steam Generator (HRSG) to generate more steam which passes through Steam Turbine $(S T)$ to obtain shaft work $\left(\dot{W}_{S T}\right)$. Saturated water flows through pump (P) in order to increase pressure and then passed through HRSG, which then completes the Rankine cycle.

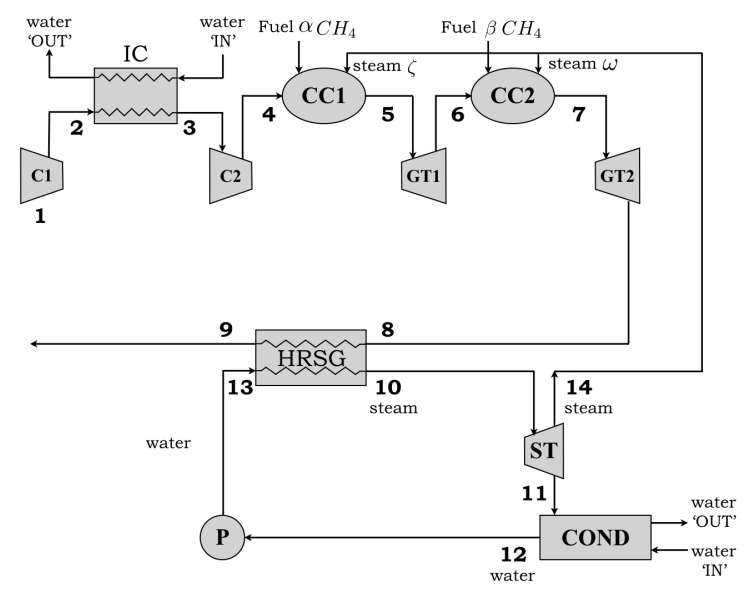

Figure 1. Schematic diagram of configuration 1,2 and 3 (Listen in Table-1)

The configuration \#2 has basic schematic same as configuration $\# 1$, except a fraction of steam $(\zeta)$ is extracted from $S T$ and injected inside combustion chamber $C C 1$ with air and fuel. The fraction of steam $\zeta$ is percentage of air mass flow which enters combustion chamber $C C 1$ at state 4 . The steam $\zeta$ is then taken out from steam turbine at the stage where steam pressure is $5 \%$ higher than pressure of combustion chamber 1 (CC1). The configuration \#3 is an extension from configuration
$\# 2$, where fraction of steam $(\omega)$ is injected inside of reheater combustion chamber (CC2). Steam is taken out of steam turbine at $5 \%$ higher pressure present inside combustion chamber 2 (CC2).

TABLE II. FUEL BALANCE ON $C C 1$ AND $C C 2$ FOR CONFIGURATION \#1.

\begin{tabular}{|c|c|c|c|c|c|c|c|c|c|c|}
\hline 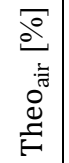 & $\frac{\sigma}{d}$ & 7 & $\begin{array}{l}\Xi \\
0 \\
\Xi \\
E \\
E\end{array}$ & $\stackrel{2}{\infty}_{\infty}^{5}$ & $\frac{\sqrt{0}}{3}$ & 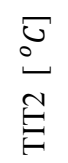 & $\frac{\sqrt{2}}{\stackrel{5}{ \pm}}$ & $\begin{array}{l}\frac{3}{3} \\
3\end{array}$ & $\frac{\sum_{i}^{\Delta}}{s}$ & $\underbrace{\sum_{\vec{u}}}_{\vec{\Delta}}$ \\
\hline 200 & U & 0 & J & 60 & 0 & 222 & .58 & 50363 & 146469 & J40 \\
\hline 200 & 2.22 & 0 & 1074 & 57.78 & 0 & 217 & 44.01 & 250363 & 145701 & 353 \\
\hline 200 & 4.44 & 0 & 1095 & 55.56 & 0 & 1213 & 44.64 & 250363 & 144921 & 35813 \\
\hline 200 & 6.67 & 0 & 1116 & 3.33 & 0 & 1208 & 45.26 & 250363 & 144128 & 36315 \\
\hline 200 & .89 & 0 & 37 & 1 & 0 & 1204 & 45.89 & 250363 & 143321 & 3681 \\
\hline 200 & .1 & 0 & 57 & 48.89 & 0 & 99 & 46.51 & 2. & 2502 & 3731 \\
\hline 200 & .33 & 0 & 178 & 46.67 & 0 & 1194 & 47.13 & 25 & 141670 & 378 \\
\hline 200 & 55.56 & 0 & 1198 & 44.44 & 0 & 1189 & 47.74 & 250363 & 140824 & 38302 \\
\hline 200 & 57.78 & 0 & 1218 & 42.22 & 0 & 1184 & 48.35 & 250363 & 139966 & 387939 \\
\hline 200 & 60 & 0 & 1238 & 40 & 0 & 1179 & 48.9 & 250363 & 139094 & 39283 \\
\hline
\end{tabular}

\section{B. Thermodynamic Analysis and Methodology}

For the considered configurations energy and exergy analyses are conducted with steam injection in gas turbine combustion chambers. Equations are developed for the configurations and the role of steam injection and effect of operating variables are simulated on performance and carbon dioxide emissions..

TABLE III. FUEL BALANCE ON CC1 AND CC2 FOR CONFIGURATION \#3.

\begin{tabular}{|c|c|c|c|c|c|c|c|c|c|}
\hline 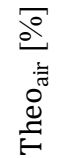 & $\frac{\sqrt{0^{2}}}{\sim}$ & 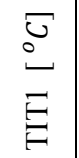 & $\frac{d^{\circ}}{3}$ & $\begin{array}{l}\tilde{U} \\
\stackrel{0}{\mathcal{E}} \\
\underline{E}\end{array}$ & $\frac{\partial^{2}}{\equiv}$ & $\begin{array}{l}\frac{3}{z} \\
30\end{array}$ & $\frac{\substack{u \\
\text { s. }}}{3}$ & $\frac{3}{3}$ & 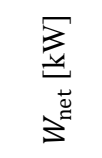 \\
\hline 00 & 1 & 173 & 1 & 69 & 6.93 & 2503 & & 1367 & \\
\hline 00 & 2 & 62 & 2 & 146 & 6.52 & 0363 & 492031 & 014 & 373246 \\
\hline 200 & 3 & 1152 & 3 & 1123 & 46.08 & 250363 & 493950 & 127296 & 369729 \\
\hline 200 & 4 & 12 & 4 & 02 & .62 & 3 & 8 & 66 & 36500 \\
\hline 200 & 5 & 132 & 5 & 1081 & 45.13 & 250363 & 495575 & 117824 & 36206 \\
\hline 200 & 6 & 122 & 6 & 1061 & 44.61 & 250363 & 496115 & 113068 & 357934 \\
\hline 200 & 7 & 1112 & 7 & 1042 & 44.08 & 250363 & 496490 & 108297 & 353627 \\
\hline 200 & 8 & 103 & 8 & 1023 & 43.52 & 250363 & 496710 & 103510 & 349152 \\
\hline 200 & 9 & 1094 & 9 & 1005 & 42.94 & 2503 & $496^{\circ}$ & 98707 & 344516 \\
\hline 0 & 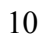 & 1085 & 10 & 87.5 & 42.34 & 250363 & 496729 & 93886 & 339730 \\
\hline
\end{tabular}

All simulations have been conducted using Engineering Equation Solver (EES).

Identify applicable sponsor/s here. (sponsors) 


\section{RESULTS AND DisCUSSIONS}

\section{A. Effects of pressure ratio on combined performance with fraction of steam injection}

The effects of pressure ratio on combined cycle for both thermal and exergy efficiency is shown in Fig 2. It can be seen from Fig. 2 that there is a sharp increase in thermal efficiency for initial pressure ratio range from 5 to 25 . For configuration $\# 1$, there is a reduction in thermal efficiency corresponding to pressure ratio of 25 to 40 whereas for configurations \#2 and \#3, there is no such noticeable reduction in thermal efficiency after optimum pressure ratio has reached. Furthermore it can be seen from Fig. 2 that there is an increase of $1.57 \%$ exergy efficiency corresponding to $5 \%$ steam injection in $C C 1$ and $C C 2$.

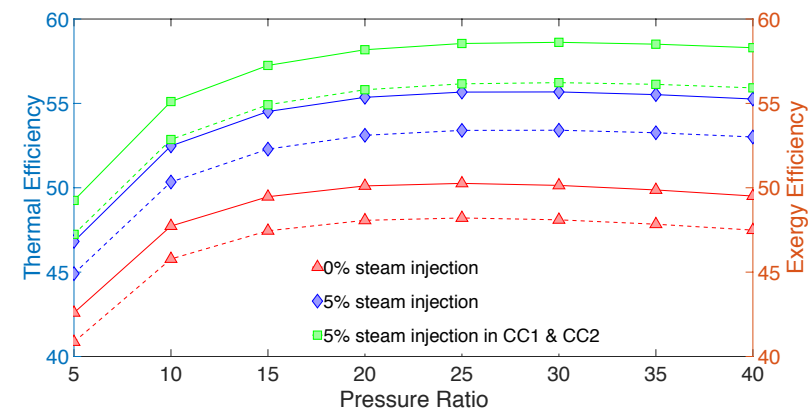

Figure 2. Effects of pressure ratio on combined cycle for both thermal (solid line) and exergy efficiency (broken line)

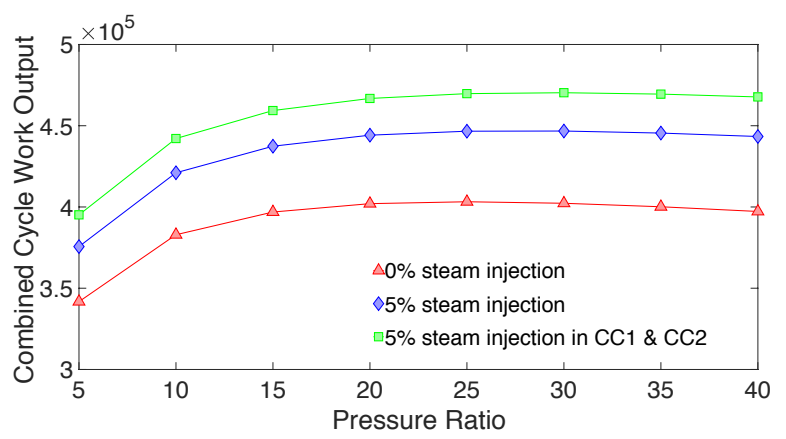

Figure 3. Effects of pressure ratio on the combined cycle work output

\section{B. Effects on $\mathrm{CO}_{2}$ emission with fraction of steam injection}

Amount of fuel reduction with steam injection has direct impact on $\mathrm{CO}_{2}$ emissions. The operating parameters of the combined system are set as pressure ratio $=25$, Ambient temperature $=25^{\circ} \mathrm{C}$, Ambient pressure $=1$ bar, Steam temperature $=500{ }^{\circ} \mathrm{C}$ and Steam pressure $=100$ bar. The effects of steam injection on $\mathrm{CO}_{2}$ emission is shown in Fig. 4. When steam $\zeta$ is injected to $C C 1$, a constant TIT1 is maintained through reduction on air mass flow, thus reduction in compressor work. At this flow rate, combined cycle net work output increase by $3.2 \%$, because of increase in mass flow of the steam from $0 \%$ to $10 \%$ in $G T 1$. In order to maintain constant combined cycle work output, fuel $(\alpha)$ consumption reduces. And when steam $\omega$ is injected in CC2 only, mass flow rate affects only GT2 and through reduction of fuel $\beta$ in $\mathrm{CC} 2,7.2 \%$ of $\mathrm{CO}_{2}$ emission reduction observed. However, when steam $\zeta$ and $\omega$ were injected in $C C 1$ and $C C 2$ together, only $0.9 \%$ of $C_{2}$ emission was observed. The results indicates that injecting steam in $C C 2$ alone has greater effects on reduction of $\mathrm{CO}_{2}$ emissions.

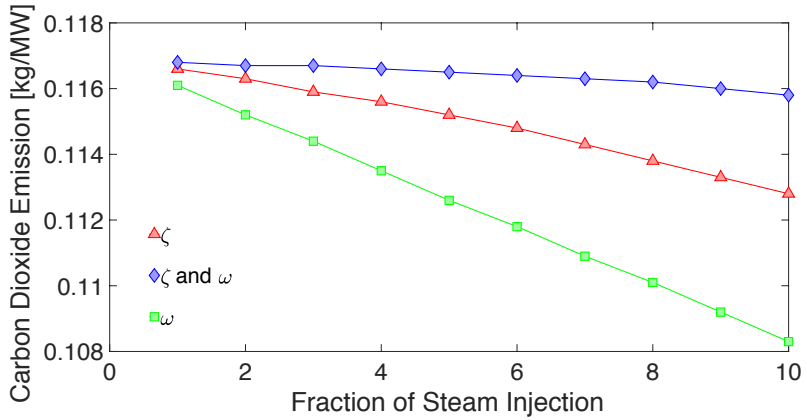

Figure 4. Effects of steam injection in $C C 1$ and $C C 2$ on Carbon Dioxide Emission.

\section{Performance analysis on fuel ratio for combined cycle with fraction of steam injection}

Table II shows fuel supply ratio between $C C 1$ and $C C 2$.At pressure ratio of 25 and Theo $_{\text {air }}$ of $200 \%$, ideal fuel supply is $\alpha=54 \%$ and $\beta=46 \%$. At this fuel supply TIT 1 and TIT 2 are very close to each other, which then becomes and important factor to gas turbine efficiency. Furthermore, Table III shows steam $\zeta$ and $\omega$ injected at $C C 1$ and $C C 2$ respectively. As steam $\zeta$ injected in $C C 1$, there is a reduction in TIT1 due to increased mass from the steam, which further resulting in reduction of flame temperature. There is a sharp reduction in TIT1 of $88^{\circ} \mathrm{C}$ with $10 \%$ steam injection in CC1. Further addition of steam $\omega$ in CC2 resulting further reduction of TIT2. Work output of the gas turbines are increased about $5 \mathrm{MW}$ but sharp decline in the net work output (37MW) due to work output lost from the steam turbine. Furthermore Table III shows ideal theoretical air input at different steam injection to maintain the same net work output. Theoretical air is reduced by $32 \%$. It is assumed that complete combustion takes place in both $C C 1$ and $C C 2$. Steam injection decreases the amount of excess air in the combustion chamber, which also supports in controlling the temperature. The amount of steam injection has a limit depending on the air quality on the compressor. As a result of decreased fuel mass, the flue gas from the combustion chamber decreases resulting reduction in $\mathrm{CO}_{2}$ and $\mathrm{NO}_{2}$ emission (Fig. 4).

\section{Exergy destruction in combined cycle system}

Figure 6 shows exergy destruction in each individual component in combined cycle compared to overall exergy destruction in the cycle. These results corresponds to fixed turbine inlet temperature of $1200{ }^{\circ} \mathrm{C}$ and pressure ratio of 25 . The main source of exergy destruction in the combined cycle unit are the main combustion chamber $(C C 1)$, reheat combustor 
(CC2) and heat recovery steam generator (HRSG) which are responsible for $37 \%, 20 \%$ and $16 \%$ respectively of the total exergy destruction. It can be seen from the Fig. 6 that the combustors of topping cycle have the highest exergy destruction. Moreover, reducing the destruction in the combustors of topping cycle will lead to a significant improvement in the exergetic efficiency and also reduced destruction in the combined cycle.

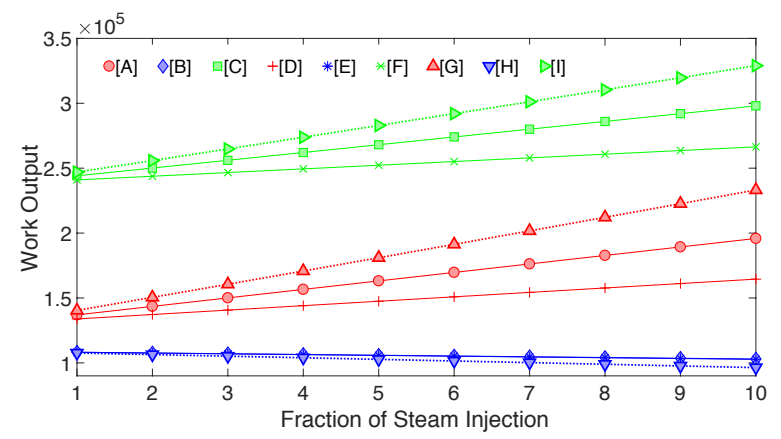

Figure 5. Effects o work output with steam injection for Configuration \#1, \#2 and $\# 3$.

TABLE IV. EFFECTS OF WORK OUTPUT WITH STEAM INJECTION FOR CONFIGURATION \#1, \#2 AND \#3 (FIG. 5).

\begin{tabular}{|c|l|c|}
\hline & \multicolumn{1}{|c|}{ Work Output } & Steam injection in: \\
\hline$[\mathrm{A}]$ & Gas Cycle Work Output & $C C 1$ \\
\hline$[\mathrm{B}]$ & Steam Cycle Work Output & $C C 1$ \\
\hline$[\mathrm{C}]$ & Combined Cycle Work Output & $C C 1$ \\
\hline$[\mathrm{D}]$ & Gas Cycle Work Output & $C C 2$ \\
\hline$[\mathrm{E}]$ & Steam Cycle Work Output & $C C 2$ \\
\hline$[\mathrm{F}]$ & Combined Cycle Work Output & $C C 2$ \\
\hline$[\mathrm{G}]$ & Gas Cycle Work Output & $C C 1$ and $C C 2$ \\
\hline$[\mathrm{H}]$ & Steam Cycle Work Output & $C C 1$ and $C C 2$ \\
\hline$[\mathrm{I}]$ & Combined Cycle Work Output & $C C 1$ and $C C 2$ \\
\hline
\end{tabular}

The exergy destruction in the combustion chamber is related to chemical reaction that occurs in combustion process. The exergy destruction ratios that associated with both turbines are less than $10 \%$ of total exergy destruction of the power plant. Although the rejected heat in the condenser is considered as tremendous amount from first law of thermodynamics perspective, the exergy destruction ratio associated with the condenser unit is low because the steam at condenser condition does not have potential power to produce useful work. As the fraction of steam (5\%) injected in $C C 1$ and $C C 2$, there is a drop of exergy destruction in $C C 1$ and $C C 2$ by $2.3 \%$ and $2 \%$ respectively. Steam injection adds more useful work and lowers the requirement of fuel amount in combustion chamber, that further reduces the destruction.

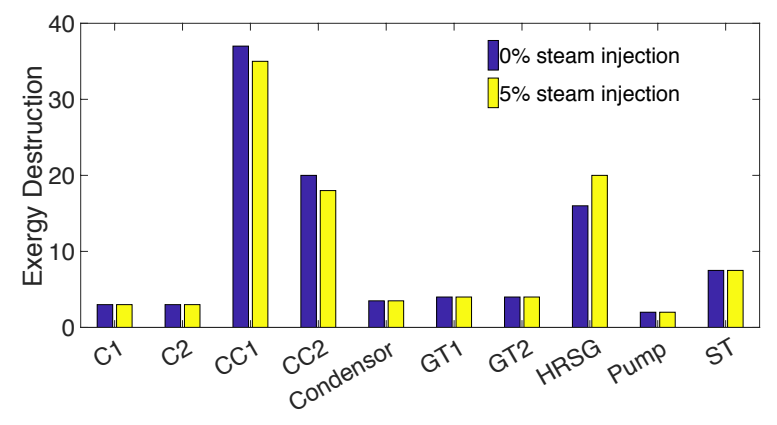

Figure 6. Percentage of exergy destruction in each component as compared to overall destruction on combined cycle with steam injection.

\section{CONCLUSIONS}

It is observed that the steam injection increases gas cycle efficiency and decreases the steam cycle efficiency. Ideal pressure ratio found to be 25 for considered combined cycle power generation configurations. Steam injection in main combustion chamber and reheat combustion chamber individually has more benefit than steam injection in both combustion chambers together. Maximum $\mathrm{CO}_{2}$ emission reduction $(7.2 \%)$ occurs when steam injected in reheat combustion chamber Thermal efficiency of combined cycle system increased by $8.2 \%$ when $10 \%$ steam injection in both combustion chambers. The present results and trends on steam injection effect on work output and efficiency are in agreement with results reported in the literature.

\section{REFERENCES}

[1] Srinivas, T., A.V.S.S.K.S., Gupta, B.V. Reddy., Parametric simulation of steam injected gas turbine combined cycle, Journal of Power and Energy, Part A, (Proceedings of the Institution of Mechanical Engineers), 221, pp. 873-883, 2007

[2] Waldyr, L.R.G., Comparison between the HAT cycle and other gas turbine based cycles, efficiency, specific power and water consumption, Energy Conversion and Management, 38, pp. 1595-1604, 1997.

[3] Nishida, K., Takagi, T., Shinichi, K., Regenerative steam injection gas turbine systems, Journal of Applied Energy, 81, pp. 231-246, 2005.

[4] Shukla, A.K., Singh, O., Thermodynamic analysis of steam injected gas turbine cycle power plant with inlet air cooling, International Journal of Ambient Energy, 38, pp. 556-566, 2017.

[5] Bahrami, S., A. Ghaffari, M. Genrup., M. Thern., Performance comparison between steam injected gas turbine and combined cycle during frequency drops, Energies, 8, pp. 7582-7592, 2015.

[6] Korakianitis, T., J. Grantstrom., P. Wassingbo, A. F. Massardo., Parametric performance of combined-cogeneration power plants with various power and efficiency enhancements, Journal of Engineering for Gas Turbines and Power 127, pp. 65-72, 2005. 